\title{
Efeito de danos mecânicos, da redução de temperatura e 1-MCP no metabolismo pós-colheita de brócolis Legacy
}

\author{
Effects of mechanical injury, temperature decreasing, and 1-MCP on the post-harvest metabolism of Legacy broccoli
}

\author{
Cristiane Brauer ZAICOVSKI ${ }^{1 *}$, Camila PEGORARO², Jocleita Peruzzo FERRAREZZE², \\ Joceani DAL CERO ${ }^{2}$, Daniela Guerra LUND ${ }^{3}$, Cesar Valmor ROMBALDI ${ }^{4}$
}

\begin{abstract}
Resumo
O etileno acelera o metabolismo pós-colheita de brócolis, e sua síntese é induzida por danos mecânicos e pelo aumento da temperatura. Para testar esta hipótese, foram realizados 03 experimentos. No primeiro, avaliou-se o efeito do dano mecânico na produção do etileno; no segundo, estudou-se o efeito do armazenamento refrigerado; e, no terceiro, o efeito do 1-MCP no metabolismo e conservação de brócolis.

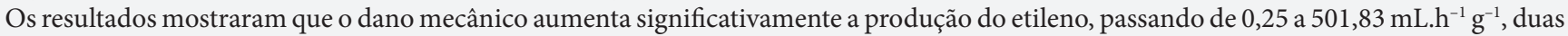
horas após a aplicação do tratamento. Já, no tratamento controle, os incrementos foram menores, passando de 0,27 para $203,13 \mathrm{~mL}^{-1} \mathrm{~h}^{-1}$. Durante o armazenamento, observou-se que a deterioração ocorreu mais rapidamente no tratamento controle $\left(20-22^{\circ} \mathrm{C}\right)$, com intenso amarelecimento, degradação de clorofilas e formação de odor desagradável. Os brócolis armazenados a 0-2 e a 5-7 ${ }^{\circ} \mathrm{C}$ mantiveram boa qualidade por 12 dias. A aplicação de 1-MCP não contribuiu para prolongar a vida-de-prateleira de brócolis Legacy a $20-22{ }^{\circ} \mathrm{C}$, não tendo havido efeito na preservação da coloração esverdeada, nem na prevenção da degradação de clorofilas.
\end{abstract}

Palavras-chave: coloração; clorofilas; amarelecimento; clorofilases; etileno.

\begin{abstract}
Ethylene increases the post-harvest metabolism of broccoli. The ethylene synthesis might be inducted by mechanical injury and temperature decrease. Therefore, 3 experiments were carried out to assess these hypotheses: 1) it was evaluated the mechanical injury effect on the ethylene production; 2) the effect of cold storage; and 3) effect of the 1-MCP on the broccoli metabolism and conservation. The results showed that the mechanical injury increased the ethylene production, from 0,25 to $501,83 \mathrm{~mL} \cdot \mathrm{h}^{-1} \mathrm{~g}^{-1}$, two hours after the injury occurrence. In contrast, in the control treatment the increments were lower, varying from 0,27 to $203,13 \mathrm{~mL} \cdot \mathrm{h}^{-1} \mathrm{~g}^{-1}$. During storage, the deterioration occurred more rapidly in the control treatment $\left(20-22^{\circ} \mathrm{C}\right)$ observing yellowing, chlorophyll degradation, and production of off-flavor. The broccolis stored in the temperature ranges of $0-2$ and $5-7^{\circ} \mathrm{C}$ maintained good quality for up to 12 days. The application of 1-MCP did not contribute to elongate the shelf life of Legacy broccoli at $20-22^{\circ} \mathrm{C}$, neither did it influence the preservation of the green color nor the avoidance of chlorophyll degradation.

Keywords: color; chlorophyll; yellowing; chlorophyllases; ethylene.
\end{abstract}

\section{Introdução}

Uma das principais alterações fenotípicas facilmente perceptíveis após a colheita de brócolis é o amarelecimento, decorrente da aceleração do metabolismo, induzida pelo etileno (KAWAMAKI; WATANABE, 1988). Além de prejudicar a aparência, reduzindo o valor comercial, tem-se observado que, quanto maior a velocidade e a intensidade com que o amarelecimento ocorre, maiores são as perdas nutricionais e das propriedades funcionais dessa hortaliça (JONES et al., 2006; MORENO et al., 2006).

É conhecido que o metabolismo pós-colheita de brócolis é caracterizado pelo incremento da produção de etileno e da taxa respiratória, e que a adoção de práticas que controlem essas vias metabólicas podem estender a vida-de-prateleira (ABLE et al., 2003; KU; WILLS, 1987). Assim, por exemplo, a redução da temperatura (SALVEIT, 1999), o controle das concentrações de $\mathrm{O}_{2}$ e de $\mathrm{CO}_{2}$ na atmosfera (KADER et al., 1989), e/ou a aplicação de 1-metilciclopropeno (1-MCP) (ABLE et al., 2003; KU; WILLS, 1999; WILLS et al., 2002), podem melhorar a conservabilidade dos brócolis.

Não obstante esses avanços, a preservação da coloração esverdeada em brócolis ainda é um desafio. As respostas à aplicação desses métodos de conservação (refrigeração, atmosfera modificada e controlada, e aplicação de 1-MCP) têm sido variadas entre cultivares e para a mesma cultivar produzida em condições edafoclimatológicas distintas, conforme previamente relatado por Wurr et al. (2002). Essa problemática tem sido citada sistematicamente pelos produtores da Região Sul do Brasil.

\footnotetext{
Recebido para publicação em 19/6/2007

Aceito para publicação em 8/5/2008 (002615)

'Departamento de Ciência e Tecnologia Agroindustrial, Faculdade de Agronomia Eliseu Maciel - FAEM, Universidade Federal de Pelotas - UFPel, CEP 96010-900,

Pelotas - RS, Brasil, E-mail: criszaicovski@ig.com.br

2 Departamento de Ciência e Tecnologia de Alimentos, Universidade Federal de Pelotas - UFPel, CEP 96010-900, Pelotas - RS, Brasil

${ }^{3}$ Faculdade de Ciências Biológicas, Universidade Luterana do Brasil - ULBRA, Cachoeira do Sul - RS, Brasil

${ }^{4}$ Departamento de Ciências dos Alimentos, Universidade Federal de Pelotas - UFPel, Pelotas - RS, Brasil

${ }^{*}$ A quem a correspondência deve ser enviada
} 
Para o processamento mínimo, intensifica-se o dano mecânico e, como conseqüência, é esperado que haja incremento da produção de etileno, acelerando ainda mais o processo de amarelecimento. Porém, com a redução da temperatura e/ou a inibição da ação do etileno, com o uso do 1-MCP, pode-se controlar o processo de amarelecimento. Por isso, buscou-se caracterizar a produção de etileno de brócolis Legacy, assim como o efeito de danos mecânicos, de temperatura de armazenamento e do 1-MCP no metabolismo e conservação dessa hortaliça.

\section{Material e métodos}

\subsection{Material vegetal}

Foram utilizadas inflorescências imaturas de brócolis (Brassica oleraceae), variedade Legacy, cultivada em lavoura comercial localizada no Município de Pelotas-RS. Todas as inflorescências de cada experimento foram colhidas no mesmo dia, no mesmo canteiro e no mesmo estádio fenológico.

\subsection{Experimento I - danos mecânicos $\mathrm{X}$ produção de etileno em brócolis Legacy}

Para avaliar os efeitos de danos mecânicos na produção de etileno, realizaram-se dois procedimentos: T1) cabeças de brócolis com aproximadamente $450 \mathrm{~g}$; e, T2) brócolis cortados em pedaços de aproximadamente $5 \mathrm{~g}$. Como variável dependente para monitorar as respostas ao dano mecânico, determinou-se a produção de etileno em intervalos de 30 minutos, durante duas horas, a partir da aplicação dos tratamentos.

Para a determinação da produção de etileno, os brócolis foram acondicionados em recipientes com capacidade de $7,3 \mathrm{~L}$. Os frascos foram hermeticamente fechados e mantidos à temperatura de $20-22^{\circ} \mathrm{C}$. Alíquotas de $01 \mathrm{~mL}$ da atmosfera foram retiradas de cada recipiente no momento da instalação do experimento e após 30, 60 e 120 minutos.

O experimento seguiu um delineamento inteiramente casualizado, segundo um esquema fatorial, compreendendo as seguintes variáveis independentes: com e sem dano mecânico, quatro coletas e três repetições. A variável dependente foi a produção de etileno.

\subsection{Experimento II - temperatura de armazenamento $e$ 1-MCP na conservação de brócolis Legacy}

Os brócolis cortados em pedaços de aproximadamente $5 \mathrm{~g}$ foram pré-resfriados até a temperatura de armazenamento, conforme o tratamento e, em seguida, acondicionados em embalagens de polivinil multicamadas (2834c) Criovac $^{\oplus}$, utilizando-se equipamento embalador Webomatic ${ }^{\oplus}$ (modelo E10CT100). Em seguida, os brócolis foram armazenados em câmara refrigerada: T1) $0-2{ }^{\circ} \mathrm{C}$; T2) $5-7^{\circ} \mathrm{C}$; T3) $10-12{ }^{\circ} \mathrm{C}$; e T4) $20-22^{\circ} \mathrm{C}$.

As amostras para avaliação foram coletadas no dia da instalação do experimento e a cada 4 dias. Para os tratamentos T1 e T2, coletaram-se amostras ate o $16^{\circ}$ dia, para o T3 até o $12^{\circ}$ dia, e para o T4 até o $4^{\circ}$ dia. Essas diferenças entre períodos de avaliação foram adotadas em função de resultados prelimi- nares, que apontaram para um avanço do período seguro de armazenamento, em temperaturas inferiores a $7^{\circ} \mathrm{C}$.

O delineamento experimental seguiu os princípios do experimento I, num esquema fatorial inteiramente casualizado, alterando-se as variáveis independentes, ou seja, temperatura de armazenamento $\left(0-2{ }^{\circ} \mathrm{C} ; 5-7^{\circ} \mathrm{C} ; 10-12^{\circ} \mathrm{C}\right.$; e $\left.20-22^{\circ} \mathrm{C}\right) \mathrm{x}$ número de coletas $\mathrm{x}$ três repetições. Como variáveis dependentes, avaliaram-se a produção de etileno, a concentração de etileno e de $\mathrm{CO}_{2}$, no interior da embalagem, a cor, o teor de clorofilas e a atividade clorofilase.

\subsection{Experimento III - 1-MCP na conservação de brócolis Legacy}

Testou-se a aplicação de 1-MCP em brócolis armazenados a 20-22 ${ }^{\circ} \mathrm{C}$ nas seguintes condições: T1) controle, sem 1-MCP; T2) aplicação de 500 nL.L - $^{-1}$ de 1-MCP; e T3) 1000 nL.L-1 de 1-MCP. Para a aplicação de 1-MCP, prepararam-se soluções desse produto dissolvendo-o em S-dodecil sulfato de sódio (SDS) a 1\% (m/v) a $50{ }^{\circ} \mathrm{C}$. Para o preparo das soluções, visando as concentrações finais de 500 e 1000 nL.L , $^{-1}$ utilizou-se produto técnico 0,043\% $(\mathrm{m} / \mathrm{m})$ de ingrediente ativo. Os brócolis foram mantidos sob a ação de 1-MCP por 24 horas a $20-22^{\circ} \mathrm{C}$ e mantidos nessa faixa de temperatura durante os 4 dias de avaliação.

O delineamento experimental seguiu num esquema fatorial inteiramente casualizado, com as variáveis independentes concentração de 1-MCP (sem 1-MCP, 500 e 1000 nL.L ${ }^{-1}$ ) x quatro coletas $x$ três repetições. As variáveis dependentes monitoradas foram os teores de clorofilas a e b, coloração e atividade clorofilase.

\subsection{Avaliações}

\section{Produção e concentração de etileno}

A quantificação de etileno foi realizada por cromatografia gasosa, em cromatógrafo Varian, modelo 3300, equipado com uma coluna de aço inox 1/8, preparado com Porapak ${ }^{\circledast} \mathrm{N}$ e um detector de ionização de chama. As temperaturas da câmara de injeção, da coluna e do detector foram de 80 , 90 e $200{ }^{\circ} \mathrm{C}$, respectivamente. Utilizou-se uma curva-padrão obtida com uma solução de etileno White Martins ${ }^{\circledR}$ com concentração entre 10 e $100 \mu \mathrm{L} . \mathrm{L}^{-1}$. Os resultados da produção de etileno foram expressos em $\mu \mathrm{L} \cdot \mathrm{g}^{-1} \mathrm{~h}^{-1}$. Já a concentração de etileno nas embalagens foi determinada pela coleta de $1 \mathrm{~mL}$ da atmosfera gasosa, seguida de quantificação também por cromatografia gasosa, conforme descrito precedentemente. Para a concentração de etileno, as coletas foram realizadas a cada quatro dias para os tratamentos T1, T2 e T3 e, diariamente para o T4. Os resultados foram expressos em $\mu \mathrm{L} . \mathrm{L}^{-1}$.

\section{Concentração de $\mathrm{CO}_{2}$}

A concentração de $\mathrm{CO}_{2}$ foi determinada a partir da atmosfera do interior da embalagem, empregando o equipamento Agrodatalog $320 C^{\circledast}$. As coletas para determinação da concentração de $\mathrm{CO}_{2}$ seguiram os mesmos procedimentos do etileno. Os resultados foram expressos em $\mathrm{kPa}$ de $\mathrm{CO}_{2}$. 


\section{Teor de clorofilas}

Os teores de clorofila 'a' e 'b' foram determinados pelo método de Lichtenthaler (1987). Amostras de $1 \mathrm{~g}$ de brócolis foram maceradas com $5 \mathrm{~mL}$ de acetona a $80 \%(\mathrm{v} / \mathrm{v})$. O material foi centrifugado a $4000 \mathrm{~g}$ por 10 minutos e ao sobrenadante adicionou-se acetona a $80 \%(\mathrm{v} / \mathrm{v})$, até o volume final de $25 \mathrm{~mL}$. A absorbância da solução foi lida, em espectrofotômetro Ultraspec $2000^{\circledR}$, a 647 e $663 \mathrm{~nm}$. Os teores de clorofilas 'a' e 'b' foram calculados através das seguintes Equações 1 e 2:

Clorofila ' $\mathrm{a}$ ' $=12,25\left(\mathrm{~A}_{663}\right)-2,79\left(\mathrm{~A}_{647}\right)$
Clorofila ' $\mathrm{b}$ ' $=21,50\left(\mathrm{~A}_{647}\right)-5,10\left(\mathrm{~A}_{663}\right)$

Os resultados foram expressos em $\mu \mathrm{g} \cdot \mathrm{g}^{-1}$.

\section{Coloração}

A coloração superficial foi determinada pela medida dos parâmetros $\mathrm{L}^{*}$, a e b com colorímetro (Minolta CR300 ${ }^{\star}$, Osaka, Japão). A partir de dados dessas determinações, calculou-se o ângulo Hue como sendo ${ }^{\circ} \mathrm{h}=\tan ^{-1}(\mathrm{~b} / \mathrm{a})$, quando $\mathrm{a}>0 \mathrm{e} \mathrm{b}>0$, ou como ${ }^{\circ} \mathrm{h}=180^{\circ}-\tan ^{-1}(\mathrm{~b} / \mathrm{a})$ quando $\mathrm{a}<0$ e b $>0$.

\section{Atividade clorofilase}

Amostras de $40 \mathrm{~g}$ de brócolis foram homogeneizadas com o auxílio de um mixer e adicionadas de $100 \mathrm{~mL}$ de acetona. A mistura foi, então, filtrada a vácuo utilizando-se papel Whatmann ${ }^{\circledast} \mathrm{n}^{\circ} 1$, e o material retido no filtro foi mantido a 2-4 ${ }^{\circ} \mathrm{C}$, por 12 horas, com a finalidade de evaporar a acetona residual. Passado esse período, o material retido, denominado "pó-de-acetona", foi acondicionado em crio-tubos e estocado a $-80{ }^{\circ} \mathrm{C}$. Para a realização das análises, $500 \mathrm{mg}$ desse "pó-deacetona” foram suspensos em tampão fosfato a $10 \mathrm{mM}(\mathrm{pH} 7,0)$, contendo $50 \mathrm{mM}$ de $\mathrm{KCl}$ e 0,24\% (v/v) de Triton X-100.

Para a determinação da atividade da clorofilase, a mistura foi mantida em agitação por 1 hora a $0{ }^{\circ} \mathrm{C}$. Após esse período, filtrou-se a mistura em papel Whatmann ${ }^{\circledast} \mathrm{n}^{\circ} 1$ e o filtrado foi centrifugado a 16000 g por 15 minutos a $4^{\circ} \mathrm{C}$. O sobrenadante foi utilizado para a determinação da atividade enzimática, seguindo o método descrito por Funamoto et al. (2002). Na mistura contendo $0,5 \mathrm{~mL}$ de extrato, adicionaram-se $0,1 \mathrm{~mL}$ de Triton X-100 a 1,44\% (v/v), 0,2 mL de solução de acetona contendo clorofila 'a' na concentração de $100 \mu \mathrm{g} \cdot \mathrm{mL}^{-1}$ e $0,5 \mathrm{~mL}$ de tampão fosfato $100 \mathrm{mM}(\mathrm{pH} 7,5)$. A solução foi incubada em banho-maria a $25^{\circ} \mathrm{C}$ por 25 minutos e, após esse período, a reação enzimática foi interrompida pela adição de $4 \mathrm{~mL}$ de acetona. Após 10 minutos, extraiu-se a clorofila remanescente (não degradada) com $4 \mathrm{~mL}$ de hexano, e realizou-se a leitura da absorbância a $663 \mathrm{~nm}$. Como ensaio controle, realizaram-se todas as etapas citadas anteriormente, excetuando-se a adição de $0,5 \mathrm{~mL}$ de extrato, que foi substituído por $0,5 \mathrm{~mL}$ de tampão fosfato $10 \mathrm{mM}$ (pH 7,5).

Os resultados foram expressos em variação de absorbância $(\Delta \mathrm{A})$ de cada amostra, assim calculado (Equação 3):

$\Delta \mathrm{A}_{663}=$ absorbância do ensaio controle -

\subsection{Avaliação estatística}

Os dados foram expressos como médias, com os respectivos desvios padrões. As diferenças das variáveis entre os tratamentos foram avaliadas pelo Teste de Tuckey, a 5\%. As análises estatísticas foram realizadas com o auxílio do programa de computação STATISTICA 5.0.

\section{Resultados e discussão}

A produção de etileno de brócolis aumentou significativamente após a colheita (Figura 1). Esse incremento foi significativamente superior nas inflorescências submetidas a maior intensidade de danos mecânicos, ou seja, cortadas em pedaços. Nesse caso, atingiram-se valores de produção de etileno de 507,83 $\mu \mathrm{L} . \mathrm{g} \mathrm{h}^{-1}$ após duas horas de avaliação, enquanto nos brócolis mantidos inteiros, a produção máxima de etileno foi de $203,13 \mu \mathrm{L} . \mathrm{g}^{-1} \mathrm{~h}^{-1}$.

A intensa elevação da produção de etileno pode ser atribuída aos danos mecânicos, conhecidos por induzirem a transcrição de genes da ACC sintase (KENDE, 1993) e da ACC oxidase (BALAGUÉ et al., 1993), bem como das correspondentes enzimas (BALAGUÉ et al., 1993; SALVEIT, 1999). Além disso, verificou-se que o aumento da produção de etileno é rápido após a colheita, indicando que há necessidade da adoção de medidas que previnam o aumento da produção e/ ou da ação desse hormônio o mais rapidamente possível após a colheita. Essa afirmativa é feita com base em trabalhos previamente realizados (KASAI et al., 1996; KU; WILLS, 1999), que relacionam o amarelecimento com o aumento da produção e da ação do etileno.

O fato de haver aumento da produção de etileno após a colheita de brócolis não é fato novo. Kasai et al. (1996) também haviam verificado que inflorescências de brócolis produzem significativas quantidades de etileno. Porém, nenhuma referência foi encontrada citando valores tão elevados de produção de etileno, como neste trabalho. De modo geral, os dados apontam para produções de etileno de até $100 \mu \mathrm{L} \cdot \mathrm{g}^{-1} \mathrm{~h}^{-1}$. Com brócolis Legacy, atingiram-se produções cinco vezes maiores desse pa-

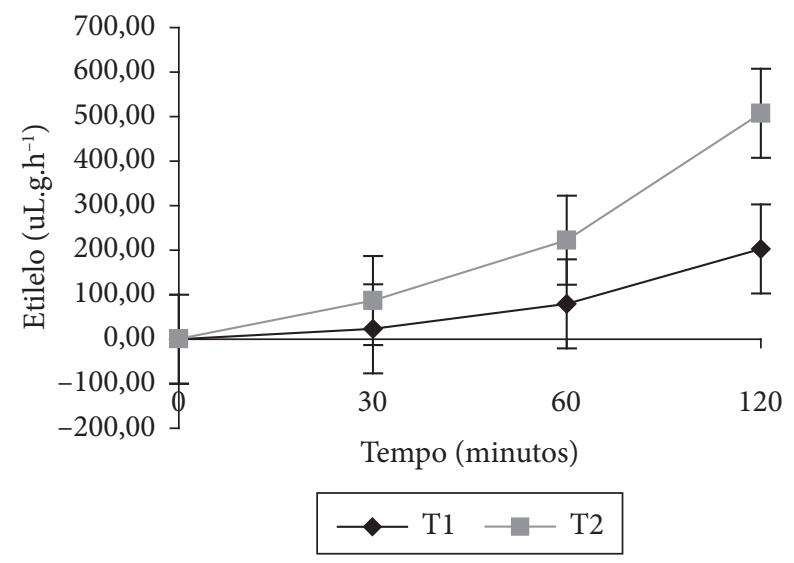

Figura 1. Produção de etileno de brócolis inteiros (T1) e cortados em pedaços (T2), mantidos a $20-22{ }^{\circ} \mathrm{C}$; e as barras indicam o desvio padrão da média. 
râmetro, quando os danos mecânicos foram aplicados. Esses resultados são importantes, pois é amplamente conhecido que o etileno é forte indutor do amarelecimento de brócolis (KASAI et al., 1996; KU; WILLS, 1999; YAMAUCHI et al., 1999), assim como da síntese de enzimas oxidativas (ALZAMORA et al., 2005; COSTA et al., 2005; KU; WILLS, 1999; MORENO et al., 2006), reduzindo o valor nutricional e funcional dessa hortaliça (JONES et al., 2006; MORENO et al., 2006). A refrigeração é uma das alternativas para reduzir a produção de etileno e prevenir o amarelecimento (KASAI et al., 1996; WATADA et al., 1996).

Para testar essa hipótese, avaliou-se o comportamento dos brócolis em diferentes temperaturas de armazenamento. Nesse caso, verificou-se que houve acúmulo de etileno e de $\mathrm{CO}_{2}$ (Figura 2) durante o armazenamento, em todos os tratamentos, porém, em maior intensidade naqueles com temperaturas mais elevadas (T3 e T4).

O efeito da temperatura foi tão marcante que, em brócolis armazenados a $20-22^{\circ} \mathrm{C}$ acumularam-se, em média, $23,12 \mu \mathrm{L} . \mathrm{L}^{-1}$ de etileno ao final de quatro dias de armazenamento, enquanto os brócolis armazenados a $0-2{ }^{\circ} \mathrm{C}$ acumularam, no máximo, $12 \mu \mathrm{L} . \mathrm{L}^{-1} \mathrm{em} 16$ dias de estocagem. Tendência similar foi observada para o $\mathrm{CO}_{2}$, ou seja, acúmulo de $0,67 \mathrm{kPa}$ em quatro dias a $20-22{ }^{\circ} \mathrm{C}$ e $0,13 \mathrm{kPa}$ a $0-2^{\circ} \mathrm{C}$ nesse mesmo período (Figura 2 ). Essa variação é coerente com o fato de que a velocidade das reações metabólicas aumenta com o aumento de temperatura (KENDE, 1993; YAMAUCHI et al., 1999).
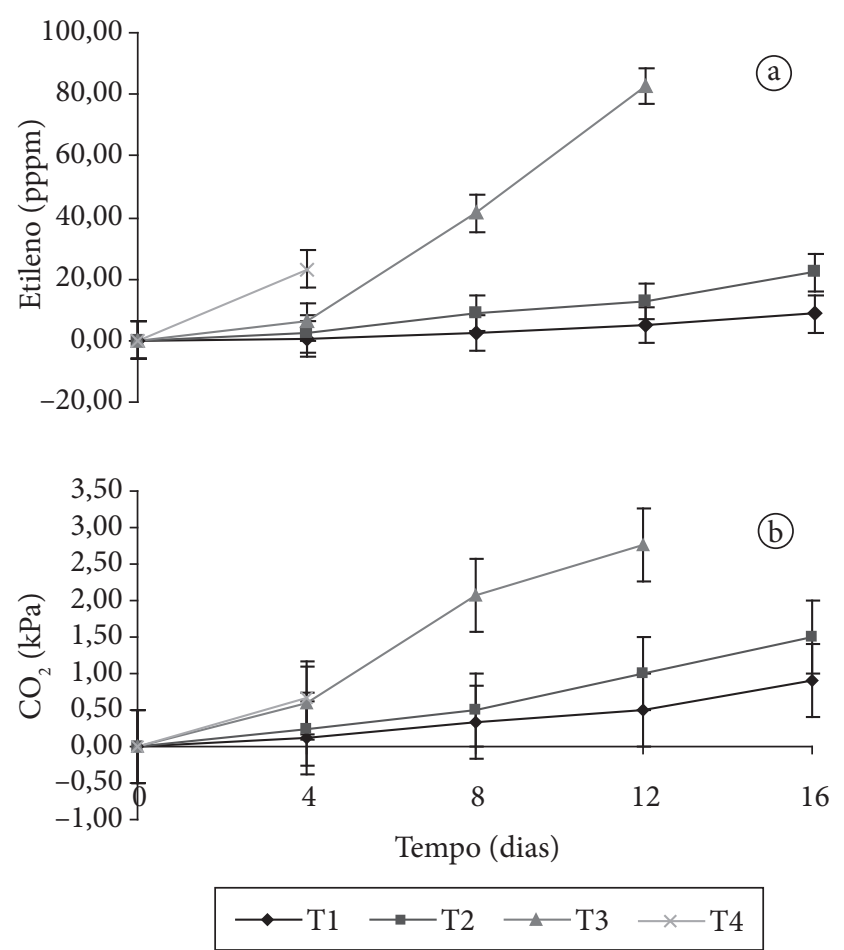

Figura 2. a) Concentração de etileno; b) $\mathrm{CO}_{2}$ no interior de embalagens de brócolis, cortados em pedaços, e armazenados a $0-2{ }^{\circ} \mathrm{C}(\mathrm{T} 1)$; $5-7{ }^{\circ} \mathrm{C}(\mathrm{T} 2) ; 10-12{ }^{\circ} \mathrm{C}(\mathrm{T} 3)$; e $20-22{ }^{\circ} \mathrm{C}(\mathrm{T} 4)$; e as barras indicam o desvio padrão da média.
Quando se avaliou o efeito da temperatura na degradação das clorofilas verificou-se que temperaturas elevadas aceleram a degradação desses compostos (Figura 3). Para melhor comprovar essa afirmativa, basta comparar o T1 $\left(0-2^{\circ} \mathrm{C}\right)$ e o $\mathrm{T} 4\left(20-22^{\circ} \mathrm{C}\right)$ (Figura 3$)$. No primeiro caso, em quatro dias de estocagem, houve redução de 3,1\% do teor de clorofila 'a' e 8,7\% de clorofila 'b'. Já, no segundo caso (T4, Figura 3), as reduções foram significativamente superiores atingindo, no mesmo período, $35,67 \%$ para clorofila 'a' e $64,62 \%$ para clorofila 'b'.

Ao avaliar-se a coloração (Figura 5), verificou-se que as maiores variações do ângulo ${ }^{\circ} \mathrm{h}$ ocorreram nos brócolis armazenados a $20-22{ }^{\circ} \mathrm{C}(\mathrm{T} 4)$, passando de valores médios iniciais de 120,00 para 100,00 em 04 dias de avaliação. Já em brócolis armazenados em temperaturas menores, (T1 e T2), não houve variação significativa durante o armazenamento. Esse comportamento é coerente com as demais variáveis, ou seja, o armazenamento em temperaturas menores $\left(0-2\right.$ e $\left.5-7^{\circ} \mathrm{C}\right)$ proporcionou menor atividade metabólica representada pelo menor acúmulo de $\mathrm{CO}_{2}$ e etileno (Figura 2), menor degradação de clorofilas (Figura 3) e menor redução no ângulo h (Figura 5).

A atividade de clorofilases mostrou-se coerente com as variações dos teores de clorofilas e da coloração. A maior atividade foi observada na avaliação inicial, logo após a colheita, com reduções de valores durante o armazenamento (Figura 7). Isso é coerente com o fato de que os danos causados durante a colheita e corte das inflorescências incrementa a produção de etileno (Figura 1), estimulando a síntese de clorofilases e resul-

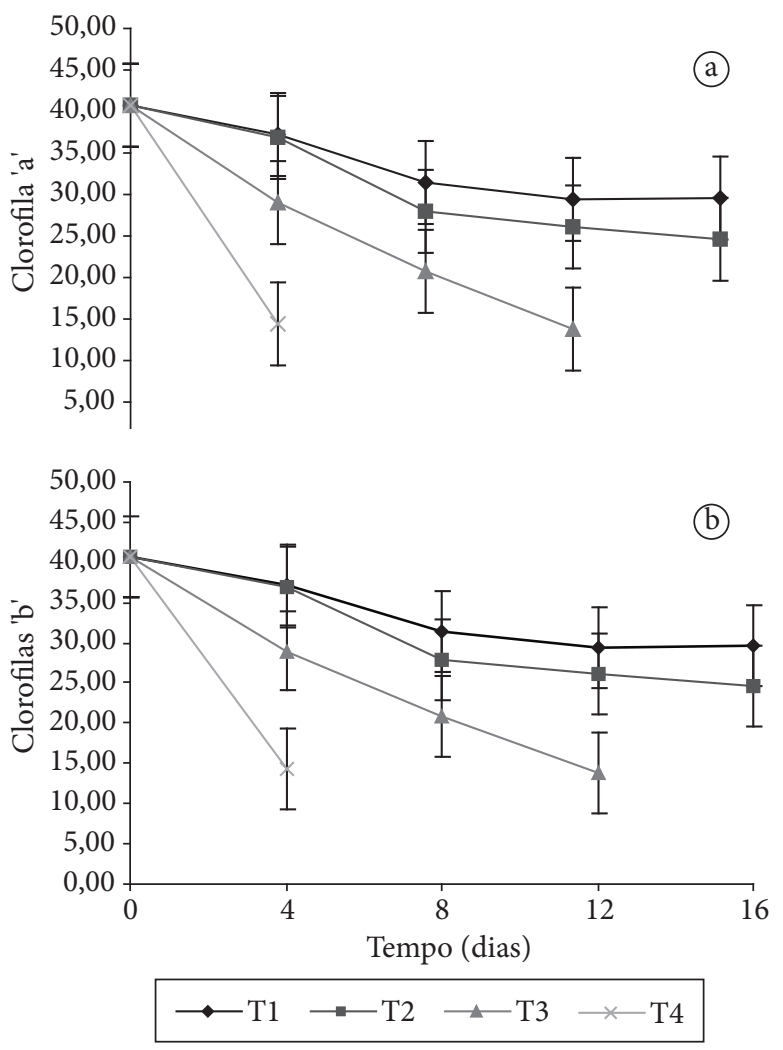

Figura 3. Teor de clorofilas 'a' e 'b' em brócolis, cortados em pedaços, e armazenados a $0-2{ }^{\circ} \mathrm{C}(\mathrm{T} 1) ; 5-7{ }^{\circ} \mathrm{C}(\mathrm{T} 2) ; 10-12{ }^{\circ} \mathrm{C}(\mathrm{T} 3)$; e $20-22^{\circ} \mathrm{C}$ (T4); e as barras indicam o desvio padrão da média. 
tando no amarelecimento (Figura 4). Funamoto et al. (2002) citam que o amarelecimento está relacionado à atividade de clorofilases, que são fortemente induzidas pelo etileno. Neste trabalho, esses autores (FUNAMOTO et al., 2002) verificaram que a atividade de clorofilase máxima ocorreu durante os primeiros quatro dias de armazenamento de brócolis a $15{ }^{\circ} \mathrm{C}$. A partir daí, a atividade de clorofilases diminuiu e o amarelecimento manifestou-se. Yamauchi, Harada e Watada (1997) já haviam observado tendência similar, embora os valores fossem diferenciados, provavelmente em função do uso de outra variedade de brócolis.

Considerando-se o fato de que os brócolis apresentam elevada produção de etileno (Figura 1) e por trata-se de uma hortaliça sensível ao etileno (KASAI et al., 1996), era esperado
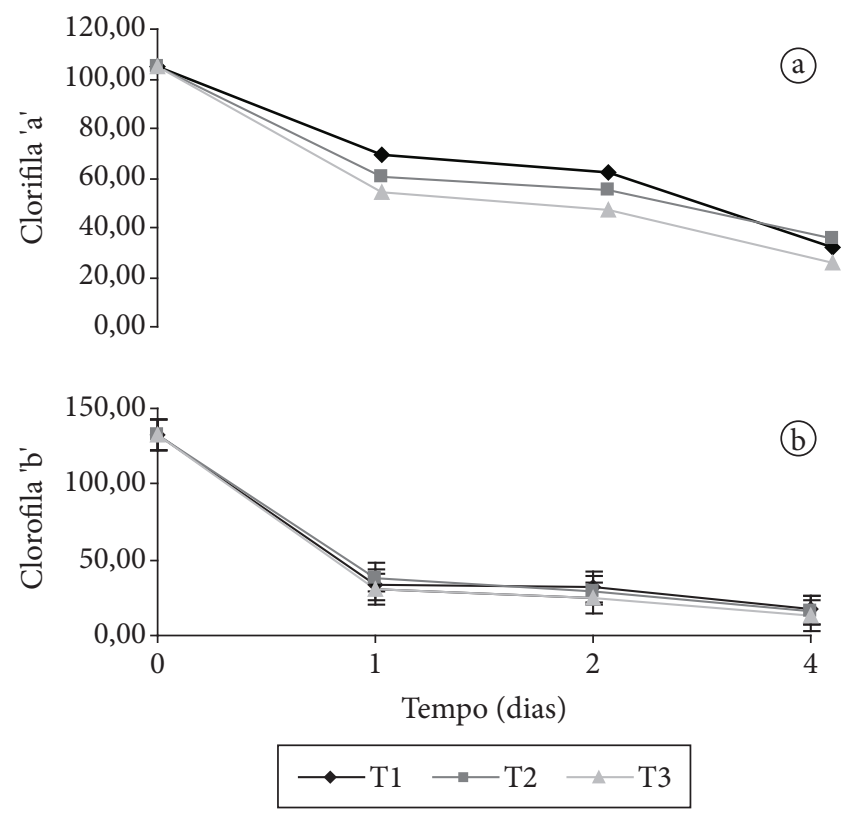

Figura 4. a) Teor de clorofilas 'a'; e b) 'b' em brócolis, cortados em pedaços, mantidos a $20-22{ }^{\circ} \mathrm{C}$, tratados sem aplicação de 1-MCP (T1), aplicação de 500 nL.L ${ }^{-1}$ de 1-MCP (T2); e 1000 nL.L $L^{-1}$ de 1-MCP (T3).

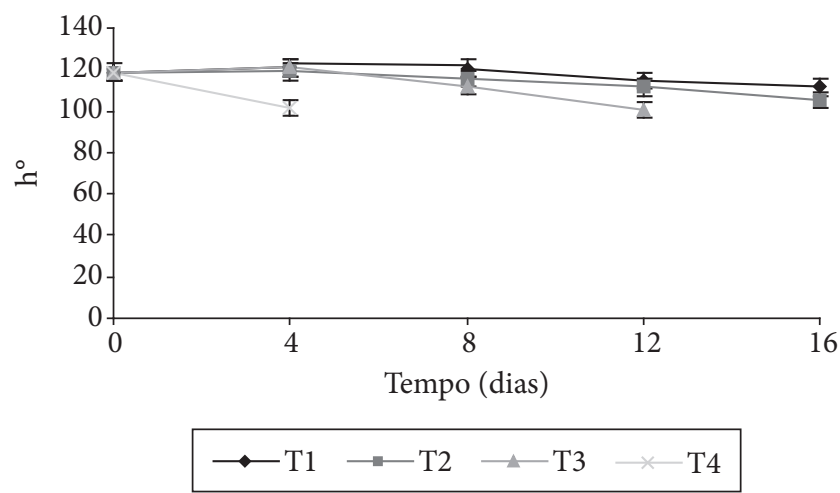

Figura 5. Ângulo Hue $\left({ }^{\circ} \mathrm{h}\right)$ de brócolis, cortados em pedaços, e armazenados a $0-2{ }^{\circ} \mathrm{C}(\mathrm{T} 1) ; 5-7{ }^{\circ} \mathrm{C}(\mathrm{T} 2) ; 10-12{ }^{\circ} \mathrm{C}(\mathrm{T} 3)$; e $20-22{ }^{\circ} \mathrm{C}(\mathrm{T} 4)$; e as barras indicam o desvio padrão da média. que a aplicação de 1-MCP pudesse proteger as inflorescências do amarelecimento. No entanto, essa resposta não foi verificada. A aplicação de 1-MCP, nas dosagens de 500 nL.L ${ }^{-1}$ (T2) e de 1000 nL.L $\mathrm{L}^{-1}$ (T3), a $20-22^{\circ} \mathrm{C}$, não proporcionou variações significativas distintas do T1, no que concerne às reduções nos teores de clorofilas 'a' e 'b' (Figura 4), coloração (Figura 6) e atividade clorofilase (Figura 8). Isso não era esperado, pois é amplamente citado que a redução da ação do etileno contribui para prevenir a coloração esverdeada (ABLE et al., 2003; KASAI et al., 1996; KADER et al., 1989; KU; WILLS, 1999; WILLS et al., 2002). A razão de não ter havido efeito da 1-MCP na prevenção do amarelecimento não está esclarecida, mas pode estar associada às condições de cultivo (WURR et al., 2002), ao genótipo ou à temperatura de armazenamento, conhecidos como fatores que afetam a sensibilidade ao etileno. Por exemplo, Wurr et al. (2002) verificaram que o cultivo com controle de aporte de água pode resultar em brócolis que preservaram melhor a coloração esverdeada, mesmo em temperatura ambiente. Costa et al. (2005) citam que o aumento da concentração de citocininas em brócolis reduz a sensibilidade ao etileno, embora aumente sua síntese.

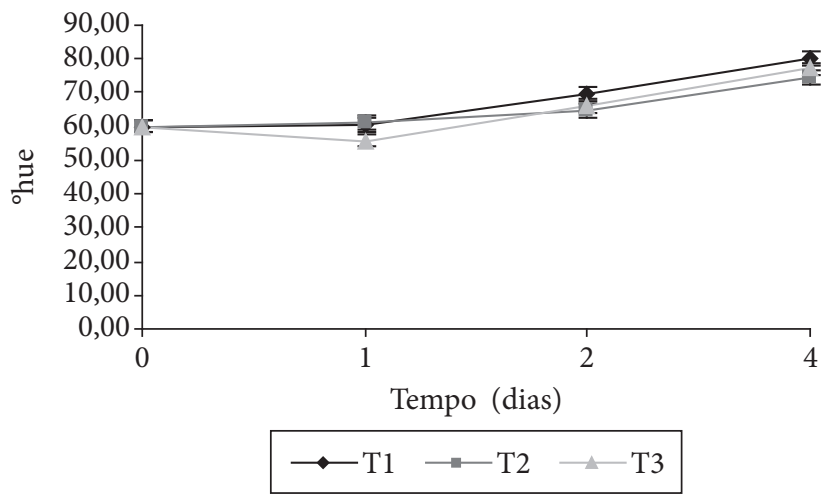

Figura 6. Ângulo Hue $\left({ }^{\circ} \mathrm{h}\right)$ de brócolis, cortados em pedaços, mantidos a $20-22^{\circ} \mathrm{C}$, tratados sem aplicação de 1-MCP (T1), aplicação de 500 nL.L. ${ }^{-1}$ de 1-MCP (T2) e 1000 nL.L L $^{-1}$ de 1-MCP (T3).

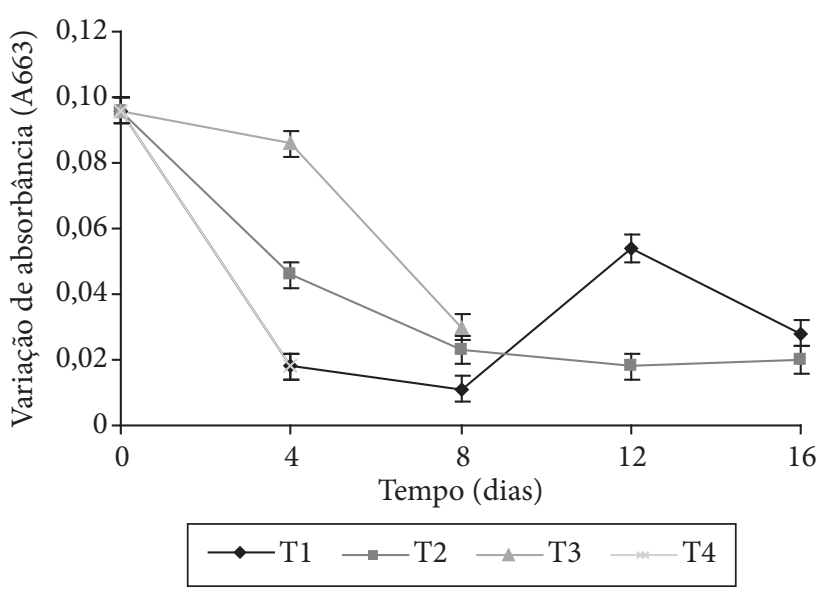

Figura 7. Atividade clorofilase em brócolis, cortados em pedaços, e armazenados a $0-2{ }^{\circ} \mathrm{C}(\mathrm{T} 1) ; 5-7{ }^{\circ} \mathrm{C}(\mathrm{T} 2) ; 10-12{ }^{\circ} \mathrm{C}(\mathrm{T} 3)$; e $20-22{ }^{\circ} \mathrm{C}$ (T4); e as barras indicam o desvio padrão da média. 


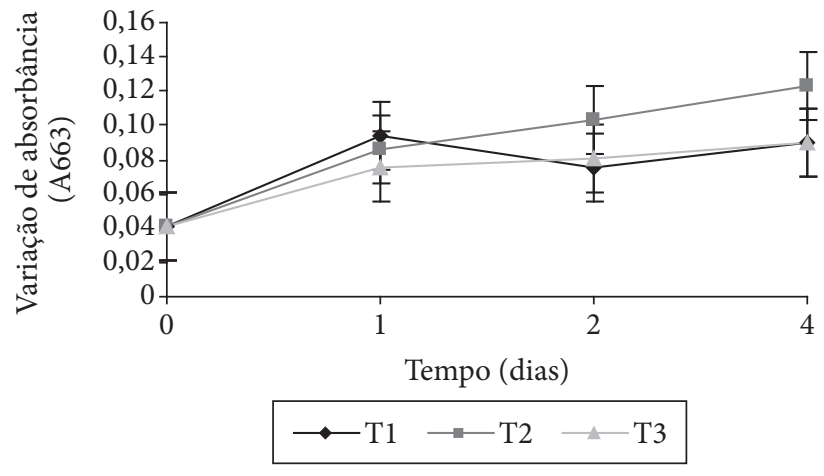

Figura 8. Atividade clorofilase em brócolis, cortados em pedaços, mantidos a $20-22^{\circ} \mathrm{C}$, tratados sem aplicação de 1-MCP (T1), aplicação de 500 nL.L ${ }^{-1}$ de 1-MCP (T2) e 1000 nL.L ${ }^{-1}$ de 1-MCP (T3).

Embora não se tenha incluído a avaliação sensorial ou determinação de compostos voláteis, pôde-se facilmente diferenciar os tratamentos pela liberação de compostos voláteis conferindo odor desagradável. Esses odores foram detectados principalmente em brócolis armazenados a $20-22^{\circ} \mathrm{C}(2$ a 3 dias de armazenamento), seguindo-se os brócolis armazenados a $10-12{ }^{\circ} \mathrm{C}$ (12 dias) e posteriormente, aqueles armazenados a 5-7 e $0-2{ }^{\circ} \mathrm{C}$ (16 dias). A aplicação de 1-MCP não contribuiu para prevenir a formação de odores desagradáveis.

\section{Conclusões}

Os brócolis Legacy apresentam elevada produção de etileno após a colheita e os danos mecânicos intensificam essa produção. $\mathrm{O}$ uso de refrigeração com temperaturas de $0-2{ }^{\circ} \mathrm{C}$ ou $5-7^{\circ} \mathrm{C}$ constitui-se num método para a conservação de brócolis, por até 12 dias. O 1-MCP não contribui para a preservação da coloração esverdeada de brócolis Legacy na temperatura de $20-22^{\circ} \mathrm{C}$.

\section{Agradecimentos}

À CAPES, pela concessão de bolsa de estudos à primeira autora, e ao $\mathrm{CNPq}$, pelo auxílio financeiro à pesquisa e pelas bolsas IC à segunda e à terceira autoras.

\section{Referências bibliográficas}

ABLE, A. J. et al. The effects of 1-methylcyclopropene on the shelf life of minimally processed leafy asian vegetables. Postharvest Biology and Technology, v. 27, n. 2, p. 157-161, 2003.

ALZAMORA, S. M. et al. Novel functional foods from vegetables matrices impregnated with biologicall active compounds. Journal of Food Engineering, v. 67, n. 1-2, p. 205-214, 2005.

BALAGUÉ, C. et al. Isolation of a ripening and wound-induded cDNA from Cucumis melo L.; with homology to the ethylene-forming enzyme. European Journal of Biochemistry, v. 212, n. 1, p. 27-34, 1993.
COSTA, M. L. et al. Effect of ethephon and 6-benzylaminopurine on chlorophyll degrading enzymes and a peroxidase-linked chlorophyll bleaching during post-harvest senescence of broccoli (Brassica oleraceae L.) at $20^{\circ} \mathrm{C}$. Postharvest Biology and Technology, v. 35, n. 2, p. 191-199, 2005.

FUNAMOTO, Y. et al. Effects of heat treatment on chlorophyll degrading enzymes in stored broccoli (Brassica oleracea L.). Postharvest Biology and Tecnology, v. 24, n. 2, p. 163-170, 2002.

JONES, R. B.; FARAGNER, J. D.; WINKLER, S. A review of the influence of postharvest treatments on quality and glucosinolate content in broccoli (Brassica oleraceae var. italica) heads. Postharvest Biology and Technology, v. 41, n. 1, p. 1-8, 2006.

KASAI, Y.; KATO, M.; HYODO, H. Ethylene biosybthesis and its involvement in senescence of broccoli florets. Journal Japanese of Horticultural Science, v. 65, n. 1, p. 153-157, 1996.

KADER, A. A.; ZAGORY, D.; KERBEL, E. E. L. Modified atmosphere packaging of fruits and vegetables. Critical Reviews in Food Science and Nutrition, v. 38, n. 1, p. 1-30, 1989.

KAWAMAKI, N.; WATANABE, A. Change in gene expression in radish cotyledons during dark-induced senescence. Plant Cell Physiology, v. 29, n. 1, p. 33-42, 1988.

KENDE, H. Ethylene biosynthesis. Annual Review of Plant Physiology and Plant Molecular Biology, v. 44, p. 283-307, 1993.

KU, V. V. V.; WILLS, R. B. H. Effect of 1-methylcyclopropene on the storage life of broccoli. Postharvest Biology and Technology, v. 17, n. 2, p. 127-132, 1999.

LICHTENTHALER, H. K. Chlorophylls and carotenoids: pigments of photosynthetic biomembranes. Methods Enzimology, v. 148, p. 350-385, 1987.

MORENO, D. A. et al. Chemical and biological characterisation of nutraceutical compounds of broccoli. Journal of Pharmaceutical and Biomedical Analysis, v. 41, n. 5, p. 1508-1522, 2006.

SALVEIT, M. E. Effects of ethylene on quality of fresh fruits and vegetables. Postharvest Biology and Technology, v. 15, n. 3, p. 279-292, 1999.

YAMAUCHI, N.; FUNAMOTO, Y.; KANETSUNE, Y. Involvement of chlorophyll degrading enzimes with chlorophyll degradation in stored broccoli (Brassica oleraceae L.) florets. Food Science of Technology Research, v. 5, n. 3, p. 300-303, 1999.

YAMAUCHI, N.; HARADA, K.; WATADA, A. E. In vitro chlorophyll degradation in stored brócoli (Brassica oleracea L. var. italica Plen.) florets. Postharvest Biology and Technology, v. 12, n. 3, p. 239-245, 1997.

WATADA, A. E.; KO, N. P.; MINOTT, D. A. Factors affecting quality of fresh-cut horticultural products. Postharvest Biology and Tecnology, v. 9, p. 115-125, 1996.

WILlS, R. B. H.; KU, V. V. V.; WARTON, M. A. Use of 1 -methylcyclopropene to extend the postharvest life of lettuce. Journal of Science Food Agriculture, v. 82, n. 11, p. 1253-1255, 2002.

WURR, D. C. E. et al. The influence of water stress during crop growth on the postharvest quality of broccoli. Postharvest Biology and Tecnology, v. 25, n. 2, p. 193-198, 2002. 